\title{
IMPLEMENTASI LITERASI INFORMASI SEBAGAI UPAYA PERPUSTAKAAN UNIVERSITAS AIRLANGGA MENDUKUNG TRI DHARMA PERGURUAN TINGGI
}

\author{
Ani Sistarina \\ Perpustakaan Universitas Airlangga \\ anisistarina@staf.unair.ac.id
}

\begin{abstract}
ABSTRAK
Tujuan dari karya tulis ini adalah memberikan gambaran singkat bagaimana pelaksanaan literasi informasi di Perpustakaan Universitas Airlangga. Penyelenggaraan Library class Perpustakaan Universitas Airlangga adalah jawaban bagi sivitas akademika untuk membantu pelaksanaan kegiatan belajar mengajar dan penyelesaian publikasi ilmiah yang menjadi prasarat kelulusan dan juga memberikan gambaran pelaksanaan kegiatan pelatihan dan literasi informasi bagi masyarakat sekitar kampus sehingga dapat meningkatkan kreatifitas dan produktifitas masyarakat. Penyediaan e-resource bagi Sivitas Akademika oleh perpustakaan buakn satu-satunya jalan bagi keberhasilan kegiatan belajar dan mengajar di Perguruan Tinggi. Pemanfaatan yang maksimal adalah kunci utama bagi keberhasilan akademik, akan tetapi tidak semua sivitas akademika memahami cara memanfaatkan sumber informasi yang disediakan oleh perpustakaan. Dibutuhkan kemampuan literasi informasi bagi sivitas akademika, untuk itu perlu adanya pelatihan yang memberikan pemahaman dan kemampuan literassi informasi dengan baik. Batasan karya tulis ini meliputi pada best practice Perpustakaan Universitas Airlangga dalam penyelenggaraan loterasi Informasi bagi sivitas akademika. Semua keberhasilan tersebut merupakan bentuk dari kemampuan literasi informasi untuk kesejahteraan.
\end{abstract}

Kata Kunci: literasi informasi, libarary class, pengabdian masyarakat, perpustakaan universitas airlangga

\section{PENDAHULUAN}

Perkembangan informasi dan teknologi membuat banyak perubahan dan pergeseran dalam berbagai lini kehidupan. Hal ini memaksa masyarakat untuk merubah cara pandang dan cara berfikir dari model yang konvensional menjadi lebih modern atau bahkan berubah menuju tatanan yang serba online dan digital, pergeseran tersebut secara otomatis merubah gaya hidup dan perilaku masyarakat yang cenderung membutuhkan pelayanan yang cepat. Memahami kebutuhan masyarakat yang berubah tersebut, perpustakaan sebagai lembaga penyedia informasi juga dituntut untuk mampu menyesuaikan diri dan meangkap kebutuhan masyarakat sebagai target pasar perpustakaan. Pun Perpustakaan perguruan tinggi yang target pasarnya adalah sivitas akademika menangkap perubahan-perubahan tersebut dengan mengupayakan penyediakan sumber-sumber informasi dan juga pelayanan digital yang dapat diakses secara online tujuh (7) hari kali dua puluh empat (24) jam atau dengan kata lain non stop services. 
Perpustakaan Universitas Airlangga (UNAIR) sebagai salah satu perpustakaan perguruan tinggi juga pelakukan perubahan dengan menerapkan layanan digital bagi pemustakanya. Perubahan tersebut diawali dengan perubahan konsep pencarian buku secara konvensional dengan menggunakan kartu katalog menjadi terotomatisasi dengan menggunakan online public access catalog (OPAC). Layanan sirkulasi yang terotomatisasi dan penyediaan sumber informasi digital atau lebih di kenal dengan database online. Perpustakaan UNAIR sebagai jantungnya pendidikan tentu harus selalu mendukung visi dan misi lembaga. Tri Dharma Perguruan tinggi adalah salah satu misi dari semua perguruan tinggi yang ada di Indonesia. Sebagai tujuan pencapaian perguruan tinggi harus mampu melahirkan generasi-generasi kreatif, inovatif, kritis, mandiri dan tangguh. Adapun 3 poin tri dharma perguruan tinggi meliputi:

1. Pendidikan dan Pengajaran

2. Penelitian dan pengembangan

3. Pengabdian kepada masyarakat

Sebagai upaya perpustakaan dalam mendukung lembaga tinggi dalam hai ini adalah universitas, maka perpustakan harus terlibat dan menjadi bagian dalam ketiga unsur tersebut. Berdasar atas hal tersebut diatas maka tulisan ini akan membahas tentang literasi informasi untuk kesejahteraan. Ruang lingkup tulisan ini adalah kegiatan-kegiatan (best practice) yang telah dilakukan di Perpustakaan UNAIR sebagai upaya mendukung pelaksanaan Tri Dharma Perguruan Tinggi. Rumusan masalah dalam tulisan ini adalah bagaimanakah pelaksanaan kegiatan literasi informasi untuk kesejahteraan di Perpustakaan Unair sebagai upaya untuk mendukung tri dharma perguruan tinggi, sehingga nantinya tulisan ini nanti akan memberikan gambaran bagaimana pelaksanaan literasi informasi guna mendukung pelaksanaan Tri Dharma Perguruan Tinggi di Universitas Airlangga. Masyarakat literat (literate society) adalah sebuah agenda besar dunia yang telah dicanangkan oleh UNESCO. Agenda besar ini terdapat dalam Sutainable Development Goals (SDGs) yang memiliki 17 tujuan dengan 169 target dan 241 indikator.(The global goals for sustainable development, n.d.)

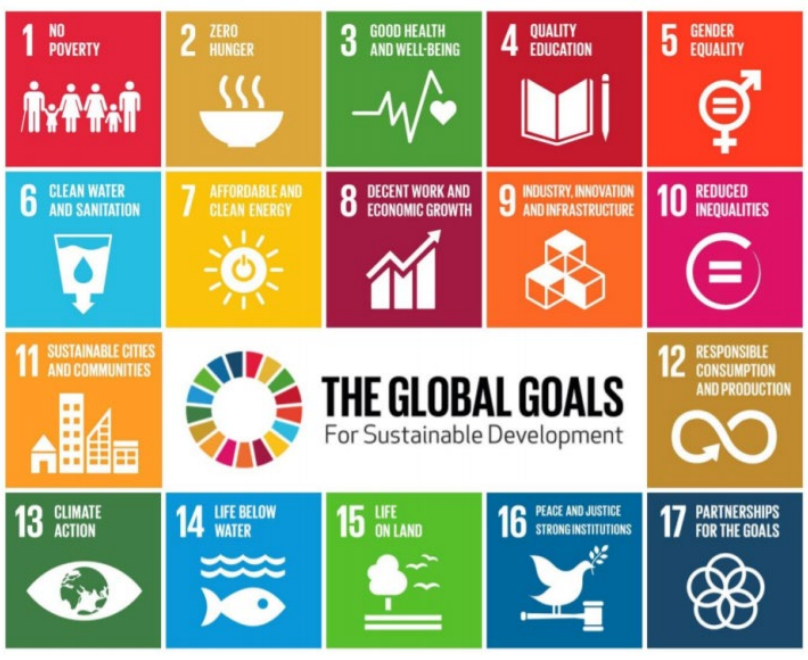

Gambar 1. The Global Goals for sustainable Development, (sumber :www.globalgoals.org) 
Dari ilustrasi diatas jelas bahwa Literasi informasi termasuk dalam tujuan ke 4 (Quality Education), kualitas dari pendidikan sudah tentu akan di tentukan juga dengan kemampuan masyarakat memahami betapa pentingnya literasi informasi menuju masyarakat yang literat.

Berbagai survei tentang minat baca telah dilakukan oleh lembaga independen di dalam dan luar negeri, Program for International Student Assessment (PISA) keluaran Organisation for Economic Co-Operation and Develompent (OECD) tahun 2015. PISA menunjukkan rendahnya tingkat literasi Indonesia dibanding negara-negara di dunia. Ini adalah hasil penelitian terhadap 72 negara. Respondennya adalah anak-anak sekolah usia 15 tahun, jumlahnya sekitar 540 ribu anak 15, dan Indonesia berada pada ranking 62 dari 70 negara yang disurvei, Berikutnya adalah peringkat literasi bertajuk 'World's Most Literate Nations' yang diumumkan pada Maret 2016, produk dari Central Connecticut State University (CCSU). CCSU merilis peringkat literasi negara-negara dunia pada Maret 2016 Indonesia berada di urutan 60 dari 61 negara yang disurvei. Indonesia masih unggul dari satu negara, yakni Botswana.(Damarjati, 2019)

Survei lain dilakukan oleh World Culture Index Score tahun 2018. Dari hasil survey tersebut menyatakan bahwa kegemaran membaca masyarakat Indonesia meningkat signifikan. Indonesia menempati urutan ke-17 dari 30 negara. Dalam hal membaca, ratarata orang Indonesia menghabisakan waktu membaca sebanyak enam jam/minggu, mengalahkan Argentina, Turki, Spanyol, Kanada, Jerman, Amerika Serikat, italia, Mexico, Inggris, Brazil, Taiwan, Jepang dengan masing-masing tiga jam/minggu.(Saepulloh, 2019) Hasil survey terbaru ini cukup menggembirakan karena adanya kenaikan,akan tetapi hal ini belumlah cukup digunakan sebagai data untuk menguatkan bahwa masyarakat Indonesia ini sudah masuk kedalam masyarakat yang literat.

American Library Association (ALA) menyatakan bahwa Information literacy adalah komponen penting bagi masyarakat dalam setiap proses pembelajaran, baik dikelas formal ataupun kelas non formal. Literasi informasi inilah yang menentukan bagaimana masyarakat dapat memiliki kompetensi dalam mengevaluasi, mengorganisir dan kemudian menggunakan informasi yang telah diterimanya. Lantas sejauh mana literasi infomasi ini mampu memberikan pengaruh terhadap kesejahteraan masyarakat. Literasi saat ini tidak hanya dimaknai secara konfensional yang hanya berkutat kepada kemampuan membaca dan menulis saja, akan tetapi literasi informasi dapat diterjemahkan sebagai solusi untuk mengatasi persoalan meningkatkan kualitas hidup dan kesejahteraan masyarakat (Alhumami, 2018). Keterbukaan akses informasi memberikan peluang pengembangan ilmu pengetahuan yang berdampak kepada peningkatan kesejahteraan.

\section{TINJAUAN PUSTAKA}

\section{Perpustakaan, Tri Dharma Perguruan Tinggi Dan Literasi Informasi untuk kesejahteraan}

Perpustakaan di perguruan tinggi memiliki peran yang sangat penting dalam upaya mendukung berjalannya seluruh kegiatan belajar dan mengajar yang dilakukan sivitas akademika. Tanggung jawab tertinggi masyarakat kampus yang literat adalah berada dipundak perpustakaan, perpustakaan berkewajiban memberikan sumber informasi yang sesuai secara cepat dan tepat bagi proises belajar mengajar di lingkungan kampus. Perpustakaan perguruan 
tinggi tidak hanya memeiliki tanggung jawab yang besar terhadap keberlangsungan kegiatan belajar mengajar dan kebuttuhan informasi yang mendukung kegiatan tersebut akan tetapi juga memiliki tanggung jawab terhadap kebutuhan informasi masyarakat di lingkungan sekitar kampus. Sebagaimana seperti disebutkan dalam 3 pilar pelaksanaan pendidikan tinggi yang di kenal dengan tri dharma perguruan tinggi.

Perpustakaan memiliki peran-peran stategis dalam pelasanaan Tri Dharma Perguruan Tinggi, peran dalam membantu pendidikan dan pengajaran, membantu pelaksanaan penelitian dan pengembangan dan juga berperan dalam pengabdian kepada masyarakat.

\section{Peran Perpustakaan Dalan Proses Pendidikan, Pengajaran Dan Penelitian}

Pemenuhan kebutuhan informasi bagi sivitas akademika adalah tujuan tersebsar bagi perpustakaan perguruan tinggi. Eksistensi sebuah perpustakaan sebagai resource center mempunyai fungsi sangat krusial dalam kegiatan akademik di perguruan tinggi. Berkolaborasi dengan tenaga edukatif sudah merupakan suatu keharusan bagi pustakawan untuk menumbuhkan academic atmosphere di perguruan tinggi (Wiratningsih, 2015)

Library education user adalah sebuah kegiatan akademik yang mampu menciptakan kemampuan literasi bagi mahasiswa. Untuk mengakses sebuah informasi mahasiswa perlu dibekali dengan keahlian (skill) dalam mencari informasi. Perpustakaan Universitas Airlangga sebagai lembaga penyedia informasi juga memiliki program library education user dengan tajuk Library Class. Penyelenggaraan Library Class di Perpustakaan Universitas Airlangga dimulai sejak tahun 2016, kegiatan ini dikelola oleh Bagian Pelatihan dan Pengembangan.

Materi yang di buat untuk Library Class mengaju kepada kebutuhan sivitas akademika dalam kegiatan belajar mengajar dan juga kebutuhan publikasi ilmiah. Materi kegiatan yang diciptakan saling terkait satu sama lainnya. Adapun materi-materi yang ditawarkan dalam Library Class adalah :(Anawati, 2019)

1. Library 101

Informasi yang disampaikan dalam materi ini meliputi pengenalan perpustakaan mulai dari tata tertib, jam buka, cara mencari buku, sampai dengan konten sumber-sumber informasi yang tersedia di Perpustakaan Universitas Airlangga. Materi ini merupakan materi dasar bagi mahasiswa baru, oleh karena itu penyampaian materi dilakukan pada saat penerimaan mahasiswa baru, khususnya mahasiswa Diploma dan S1.

2. Online Research Management (ORM)

Informasi yang disampaikan dalam materi ini meliputi: (a) pengenalan jenis dan karakteristik e-resources yang dilanggan oleh Perpustakaan Universitas Airlangga; (b) subject area masing-masing e-resources; (c) metode pencarian sumber-sumber informasi; (c) cara akses; (d) strategi pemanfaatan platform e-resources; (e) identifikasi jurnal-jurnal berkualitas.

3. Reference manager dengan aplikasi Mendeley

Informasi yang disampaikan dalam materi ini tentang mengelola literatur pendukung karya tulis secara terotomasi. Pokok bahasan yang disampaikan meliputi: (a) pembuatan akun Mendeley; (b) pengenalan fitur-fitur yang ada di website Mendeley; (c) download dan installing aplikasi Mendeley Desktop; (d) menambahkan literatur dalam Mendeley; (e) mengelola literatur; (f) mengintegrasikan Mendeley dengan aplikasi MS Word; (g) membuat sitasi dan daftar pustaka otomatis. 
4. Plagiarism checker dengan aplikasi Turnitin

Informasi yang disampaikan dalam materi ini meliputi: (a) definisi plagiarisme; (b) regulasi tentang plagiarisme; (c) strategi terhindar dari plagiarisme; (d) cek prosentase kemiripan naskah dengan Turnitin.

5. Styling dan formatting MS Word

Informasi yang disampaikan dalam materi ini meliputi: (a) merubah satuan ukuran; (b) setting lembar kerja (margin, ukuran kertas, font, spasi); (c) menggabungkan halaman romawi dengan halaman angka arab; (d) membuat daftar isi otomatis; (e) membuat daftar tabel dan gambar otomatis; (f) membuat daftar pustaka.

6. Media presentasi online dengan platform Canva. Informasi yang disampaikan dalam materi ini meliputi: (a) membuat akun pada platform Canva; (b) pengenalan fitur Canva; (c) membuat presentasi; (d) berbagi dan menampilkan karya.

\section{METODE PENELITIAN}

Dalam karya ilimiah ini penulis menggunakan metode kajian literatur dan hasil pengamatan dalam kegiatan, dimana metode ini penulis membaca dan memahami berbagai macam sumber informasi online maupun tercetak berkaitan dengan peningkatan literasi untuk kesejahteraan akademisi dan masyarakat sekitar kampus. Kajian literatur ini sangat berguna dan bermanfaat bagi penulis karena mampu mengetahui konsep-konsep secara detail dan mampu membuat kerangka berfikir khususnya dalam hal mengatur dan memilih mana referensi yang relevan dengan kajian yang dibuat (Koentjaraningrat,1983).

\section{PEMBAHASAN}

Program Library Class telah banyak dimanfaatkan baik oleh mahasiswa maupun dosen, bahkan program ini juga masuk dalam mata kuliah di beberapa program studi di Universitas Airlangga. Sebagai contoh adalah Fakultas Psikologi memasukkan materi Online Research Management (ORM), Reference manager dengan aplikasi Mendeley dalam mata kuliah Metodologi Penelitian. Berikutnya adalah Fakultas Vokasi, D3 Sastra Inggris yang memasukkan materi Online Research Management (ORM) dalam mata kuliah Research Method, S2 Magister Akuntasi-FEB, program doktoral-FKM, FISIP, Sekolah Pascasarjana. Bahkan, salah satu program Library Class (Library 101) mendapat apresiasi dari universitas, dan dimasukkan dalam materi program Pengenalan Kehidupan Kampus pada Mahasiswa Baru (PKKMB) yang dikelola oleh universitas. Library Class merupakan salah satu program unggulan Perpustakaan Universitas Airlangga (Anawati, 2019). Jumlah peserta dan kegiatan library class yang telah dilakukan oleh Perpustakaan Universitas Airlangga di jabarkan pada Tabel 1. 
Tabel 1. Daftar jumlah Library class dan jumlah Peserta

\begin{tabular}{|l|c|c|c|c|}
\hline Tahun & 2016 & 2017 & 2018 & 2019 \\
\hline $\begin{array}{l}\text { Jumlah Kelas } \\
\text { (kegiatan) }\end{array}$ & 55 & 159 & 224 & 193 \\
\hline $\begin{array}{l}\text { Jumlah Peserta } \\
\text { (orang) }\end{array}$ & 1000 & 4.453 & 5.119 & 7018 \\
\hline
\end{tabular}

Sumber : data primer yang diolah

Tabel diatas telah menjelaskan jumlah kegiatan library class dan juga jumlah pesertanya dari awal dibentuknya library class tahun 2016 hingga tahun 2019. Peningkatan peserta dan jumlah kelas yang terselenggara dari tahun ke tahun menunjukkan bahwa Library Class merupakan kegiatan yang sangat dibutuhkan oleh sivitas akademika sebagai upaya untuk meningkatkan kemampuan literasi informasi. Terlihat adanya penurunan jumlah kegiatan di tahun 2019 akan tetapi terlihat peningkatan yang siknifikan pada jumlah peserta Library Class karena diakuisisinya kegiatan Library Class ke dalam materi PPKMB UNAIR dengan kata lain kegiatan ini telah berkembang yang semula hanya kegiataninternal perustakaan kini berkembang menjadi skala universitas dan ini menjadi sebuah prestasi. Materi Library Class juga telah di bukukan dalam bentuk modul dengan tujuan untuk memudahkan sivitas akademika melakukan pembelajaran, diilustrasikan pada Gambar 2.

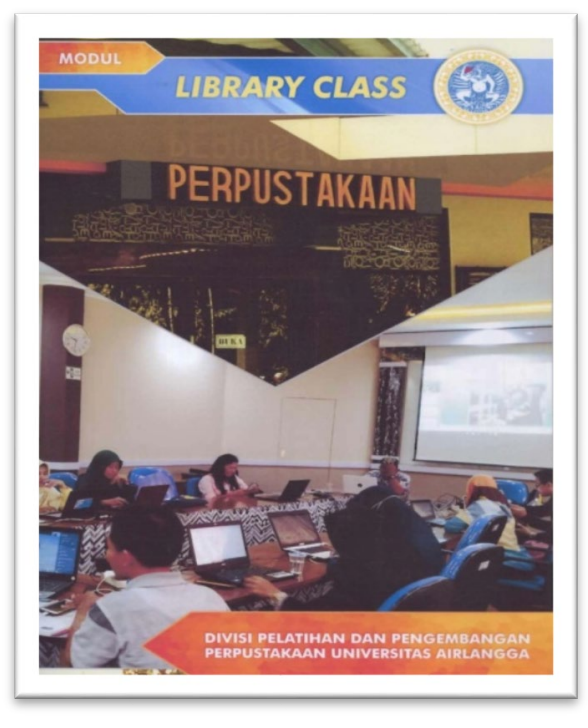

Gambar 2. Modul Library Class

Kegiatan Library Class baik offline (tatap muka) maupun online yang dilakukan di masa pandemi disikripsikan pada Gambar 3 dan 4 


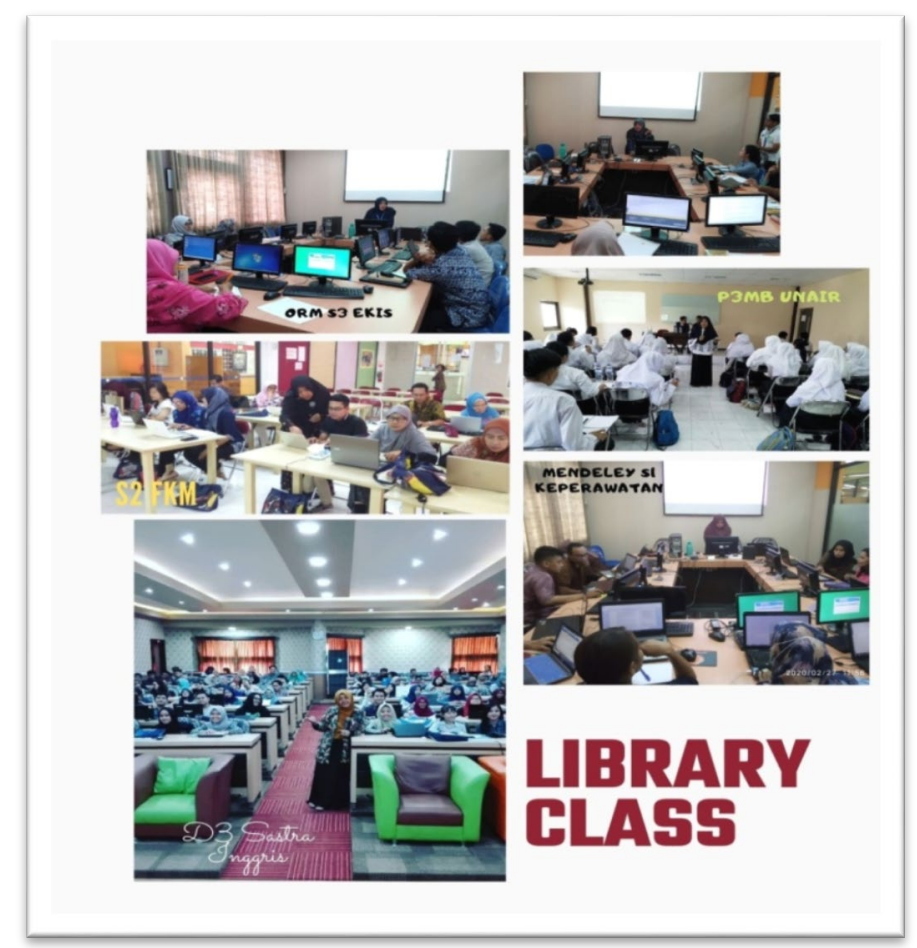

Gambar 3. Kegiatan Library Class

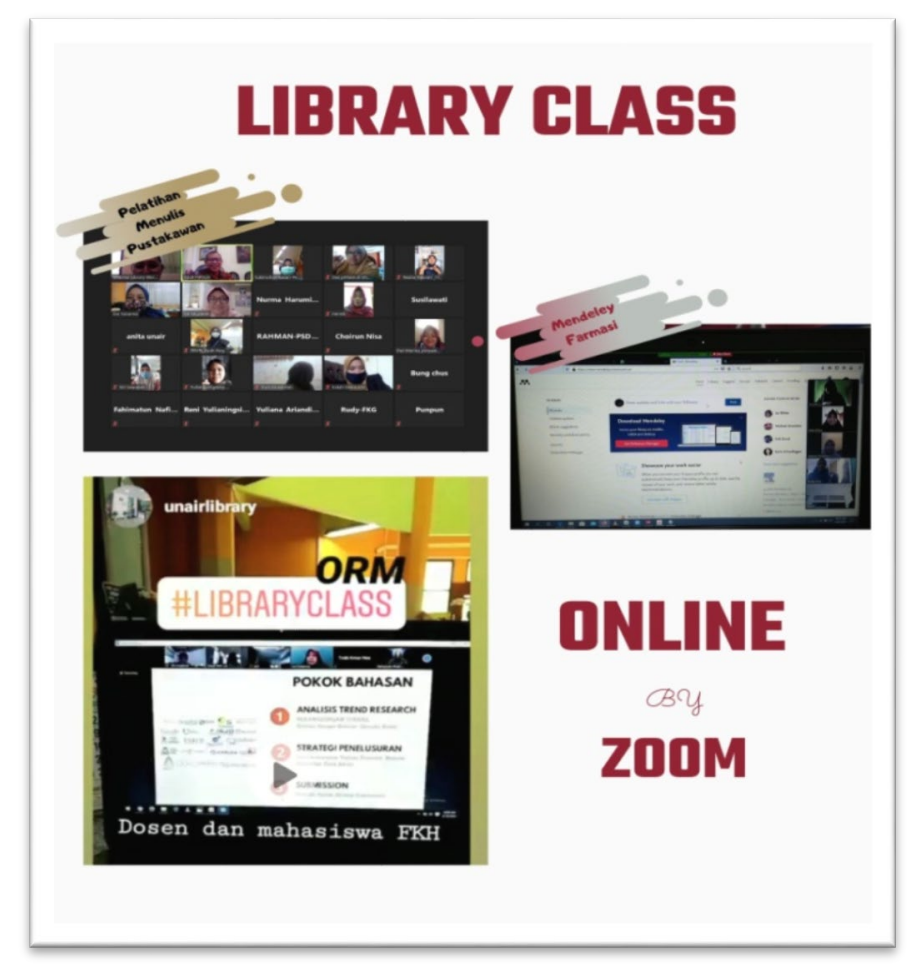

Gambar 4. Kegiatan Library Class Online di masa Pandemi

Literasi informasi di Perpustakaan Universitas Airlangga yang bertajuk Library Class telah mampu mengubah pemikiran sivitas akademika UNAIR menjadi lebih kritis dalam memilah sumber informasi yang digunakan sebagai bahan rujukan dengan mengikuti kelas Online Research Management, mampu memahami perbedaan antara e-journal dan platform pengindeksan jurnal. Penyelenggaraan kelas tersebut mampu membantu sivitas akademika 110 Jurnal Perpustakaan Universitas Airlangga - Vol. 10 No. 2 Juli - Desember 2020: 64-115 
untuk memahami dan memaksimalkan penggunaan e-resouces yang dilanggan oleh Universitas. Kemampuan memahami ini menjadi jalan untuk mempermudah publikasi bagi sivitas akademika yang menjadi sebuah prasarat kelulusan, dan membantu para peneliti dalam mengambil bahan rujukan untuk penelitian yang sedang dilakukan. Peningkatan jumlah publikasi di Scopus merupakan penanda publikasi bukan menjadi momok terbesar bagi sivitas akademika UNAIR karena pemahaman dan pemanfaatana sumber informasi yang tepat. Peningkatan jumlah publikasi yang telah terindeks Scopus dapat dilihat pada Tabel 2.

Tabel 2. Jumlah publikasi Universitas Airlangga yang terindeks Scopus

\begin{tabular}{|c|c|c|c|c|}
\hline & \multicolumn{4}{|c|}{ Tahun } \\
\cline { 2 - 5 } & 2016 & 2017 & 2018 & 2019 \\
\hline Jumlah Dokumen & 248 & 480 & 890 & 2095 \\
\hline
\end{tabular}

Sumber : www.scopus.com per 13 Juli 2020

Implementasi library class sebagai program perpustakaan sangat tepat sebagai upaya membantu dan mempermudah sivitas akademika menyelesaikan publikasi ilmiah dan juga penelitian. Keberhasilan dan kemudahan dalam publikasi dan penelitian ini tentu akan berpengaruh kepada keberhasilan akademis, dan juga adanya reward dari institusi bagi publikasi ke jurnal yang terindeks Scopus.

Library class tidak hanya di berikan untuk sivitas akademika saja akan tetapi Perpustakaan Universitas Airlangga juga menyelenggarakan kelas-kelas bagi Pustakawan untuk meningkatkan performa mereka melalui kegiatan kelompok Pustakawan. Beberapa pelatihan yang diselenggarakan untuk pustakawan adalah:

1. Pelatihan menulis karya ilmiah;

2. Pelatihan resensi buku;

3. Pelatihan scholarly communication for academic librarian;

Dan juga pelatihan dan seminar-seminar lain sebagi upaya meningkatan kemampuan pustakawan sebagai mitra sivitas akademika dalam proses belajar mengajar.

Pelatihan-pelatihan diatas yang kemudian diimplementasikan dapat memberikan dampak yang positif, beberapa keberhasilan tersebut antara lain diraihnya lomba Pustakawan berprestasi baik ditingkat daerah maupun nasional, dan juga keberhasilan pustakawan menghasilkan tulisan yang berkualitas yang diterbitkan baik di jurnal nasional maupun internasional yang terindeks oleh mesin pengindeks jurnal SCOPUS. Beberapa keberhasilan tersebut tentunya berdampak pada pemberian reword dan tentunya peningkatan kesejahteraan bagi pustakawan yang bersangkutan.

\section{Peran perpustakaan dalam pengabdian kepada masyarakat}

Pada sisi pendidikan parameter keberhasilan adalah kesuksesan dalam bidang akademis, seperti halnya keberhasilan dalam studi, keberhasilan dalam publikasi ke jurnal bereputasi yang berpengaruh juga pada reward yang didapatkan. Pada lingkungan masyarakat dimana kita juga memiliki tanggungjawab moral didalamnya, yang bisa di lakukan oleh perpustakaan perguruan tinggi adalah melakukan kegiatan pengabdian kepada masyarakat. 
Dalam pelaksanaan pelaksanaan pengabdian kepada masyarakat, Pustakawan dapat terjun langsung membina masyarakat. (Rodin, 2020)

Kegiatan pengabdian kepada masyarakat rutin dilakukan oleh pustakawan Perpustakaan Universitas Airlangga sejak tahun 2010, kegiatan ini dilakukan secara berkesinambungan hingga saat ini. Ada banyak taman baca binaan yang di buat oleh perpustakaan Universitas Airlangga dengan melibatkan pustakawan untuk terjun menjadi Pembina di setiap kegiatan yang dilakukan.

Jumlah Taman baca binaan Perpustakaan Universitas Airlangga dapat dilihat pada Tabel 3

Tabel 3. Daftar Taman Baca Binaan Perpustakaan Universitas Airlangga

\begin{tabular}{|c|l|c|}
\hline No & \multicolumn{1}{|c|}{ Tempat Taman Baca } & $\begin{array}{c}\text { Tahun } \\
\text { Berdiri }\end{array}$ \\
\hline 1 & PAUD Tunas Mandiri Gubeng & 2009 \\
\hline 2 & Tk. Islam Nabawi Jojoran & 2010 \\
\hline 3 & Pos PAUD Melati Kedung Tarukan Baru & 2010 \\
\hline 4 & Tk Melati Ceria Mulyorejo & 2011 \\
\hline 5 & Panti Asuhan Ashabul Kahfi & 2011 \\
\hline 6 & Tk. Aisiyah 06 Mulyorejo & 2011 \\
\hline 7 & Tk Handayani Pacar Kembang Surabaya & 2011 \\
\hline 8 & Ponpes Al Qodir Yogyakarta & 2013 \\
\hline 9 & SMPN 5 Mandangin Sampang Madura & 2013 \\
\hline 10 & SDN Tangir I Bojonegoro & 2014 \\
\hline 11 & SDN Ngantru Ngantang Malang & 2014 \\
\hline
\end{tabular}

Sumber Data Primer yang diolah

Kegiatan berkelanjutan dalam upaya pembinaan literasi informasi untuk masyarakat sekitar kampus beragam bentuknya sesuai dengan kebutuhan, seperti halnya : (Anawati, 2019)

1. Manjemen perpustakaan;

2. Workshop cintai lingkungan dengan go green;

3. Knowledge sharing: menumbuhkan minat baca anak;

4. Parenting class;

5. Workshop pengelolaan perpustakaan;

6. Workshop Menulis itu mudah;

7. Pelatihan merajut dengan teknik crochet;

8. Merangkai snack menjadi buket;

9. Membuat media pembelajaran dari kain flannel;

Kegiatan diatas dilakukan didalam dan diluar lokasi Perpustakaan Universitas Airlangga. Beberapa pelaksanaan kegiatan diatas dideskripsikan pada Gambar 5. 


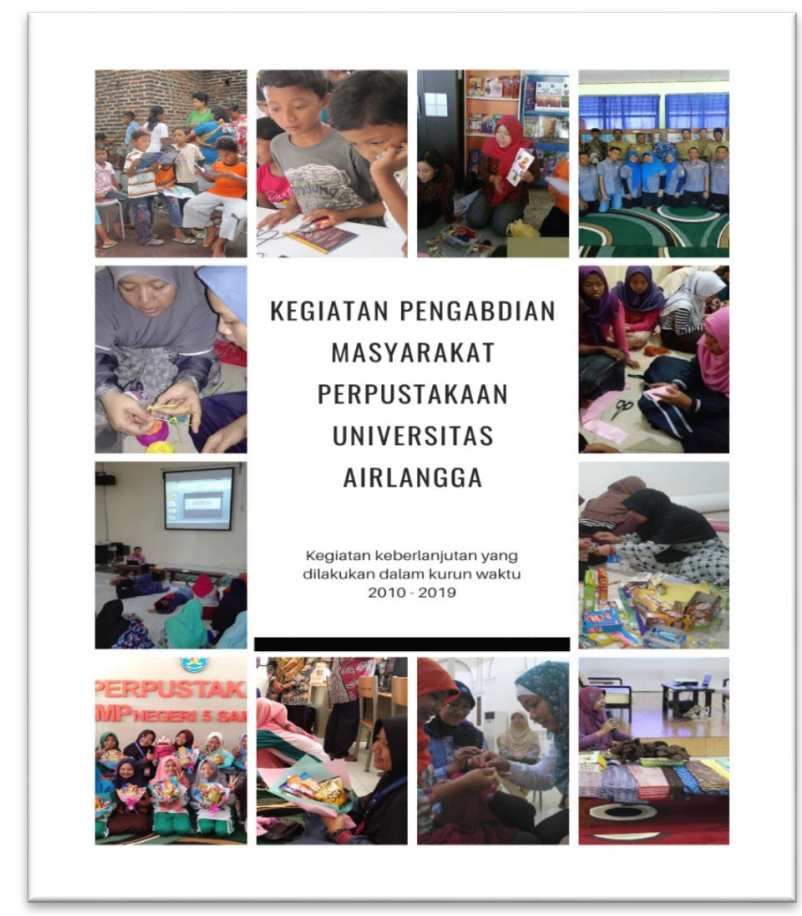

Gambar 5. Kegiatan Pengabdian Masyarakat Perpustakaan Universitas Airlangga

Kegiatan pelatihan yang diselenggarakan diatas mampu memberikan kontribusi yang nyata bagi kemandirian dan produktivitas guna meningkatkan kualitas hidup bagi masyarakat lingkungan kampus. Salah satu keberhasilan yang ditunjukkan oleh perpustakaan binaan Perpustakaan Universitas Airlangga adalah diraihnya Juara I Perpustakaan Sekolah 2012 yang diadakan Perpustakaan Daerah Surabaya. Hasil dari kreatifitas dan produktivitas masyarakat dapat di lihat pada Gambar 6.

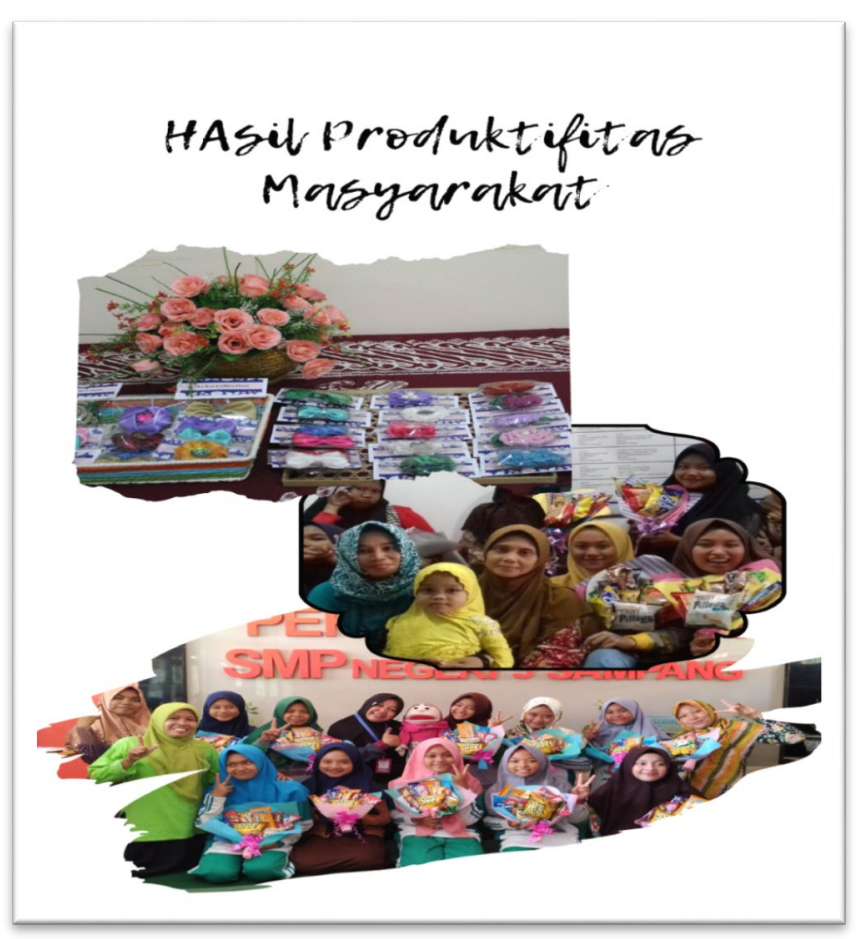

Gambar 6. Hasil produktivitas masyarakat 
Hasil produktivitas masyarakat seperti pada gambar 6.telah membantu meningkatkan kesejahteraan. Dari pelatihan yang diberikan, dan kemudian dipraktikkan yang hasilnya dipromosikan dan dijual kepada teman-teman mereka. Bros-bros cantik hasil karya anak panti asuhan putrid kenjeran juga dikemas dan dijual di took yang kelola oleh panti tersebut, sedangkan buket snack ditawarkan ketika ada agenda wisuda kelulusan disekolah dan momen ulang tahun bagi teman-teman mereka.

\section{PENUTUP}

\section{KESIMPULAN}

Kegiatan literasi informasi akan memberikan dampak yang positif bagi peningkatan kesejahteraan. Bagi sivitas akademika kemampuan literasi informasi akan memberikan banyak kemudahan dalam memilah informasi sehingga mempermudah publikasi, penelitian yang kemudian berdampak kepada keberhasilan akademis dan tentunya reword yang mengikutinya. Sedangkan kemampuan literasi informasi pada masyarakat memberikan membuat mereka lebih selektif memilah informasi yang dapat mendorong kreatifitas dan produktivitas yang tentunya berdampak pada peningkatan kesejahteraan.

\section{SARAN}

Perpindahan tempat bekerja yang semula berada di kantor ke rumah terbukti menantang bagi banyak pustakawan dan perpustakaan saat ini, karena perpustakaan diminta untuk beradaptasi dengan teknologi kolaboratif baru. Perpustakaan harus memanfaatkan momentum ini, memberikan pelatihan teknologi tambahan dan mengidentifikasi keterampilan teknologi bagi pustakawan dalam keadaan normal baru ini. Pustakawan saat ini dimobilisasi oleh media sosial untuk mendokumentasikan bagaimana perpustakaan menanggapi COVID-19, serta untuk berkembang dalam realitas baru ini, perpustakaan harus lebih gesit dan lebih responsif daripada sebelumnya. Perpustakaan Unair telah belajar dan tumbuh dalam berbagai kegiatan selama masa pandemik ini dan melakukan transformasi masa depan.

\section{DAFTAR PUSTAKA}

Alhumami, A. (2018). Tak Hanya Membaca, Literasi Juga Berkontribusi untuk Kesejahteraan Ekonomi. Retrieved July 5, 2020, from https://news.okezone.com/read/2018/02/20/65/1862022/tak-hanya-membaca-literasijuga-berkontribusi-untuk-kesejahteraan-ekonomi

Anawati, N. D. (2019). Implementasi Library Class Di Perpustakaan Universitas Airlangga. Media Pustakawan, 26(4), 329-339.

Damarjati, D. (2019). Benarkah Minat Baca Orang Indonesia Serendah Ini? Retrieved July 2, 2020, from detikNews website: https://news.detik.com/berita/d-4371993/benarkahminat-baca-orang-indonesia-serendah-ini

Rodin, R. (2020). Penguatan Peran Perpustakaan Perguruan Tinggi. Retrieved June 30, 2020, from

duniaperpustakaan.com

website: 
https://www.duniaperpustakaan.com/2020/03/penguatan-peran-perpustakaanperguruan.html\#: :text=Peran Perpustakaan dalam Aspek Penelitian\&text=Dalam Surat Keputusan Menteri Pendidikan,pelaksanaan tri dharma perguruan tinggi.

Saepulloh, R. (2019). Literasi Indonesia Ranking Terbawah Kedua di Dunia. Retrieved July 2, 2020, from warta ekonomi.co.id website:

https://www.wartaekonomi.co.id/read224647/literasi-indonesia-ranking-terbawahkedua-di-dunia

The global goals for sustainable development. (n.d.). THE 17 GOALS. Retrieved July 1, 2020, from http://www.globalgoals.org/

Wiratningsih, R. (2015). Literasi Informasi di Perguruan Tinggi (Akses E-Journal UPT Perpustakaan UNS). E-Journal UPT Perpustakaan UNS, 1-22. 